\title{
HEALTH STATUS OF SCHOOL CHILDREN OF POKHARA VALLEY, NEPAL
}

\author{
Shrestha L*, Khattri J B K
}

\section{ABSTRACT}

The cross sectional study to assess the health and nutritional status of school children in the age group of 4-15 years was carried out in 6 government primary schools of Pokhara valley by health team of the department of Social \& Preventive Medicine (SPM), Manipal College of Medical Science, Pokhara, Nepal. A total of 750 students of both sexes, 368 boys and 382 girls were examined. The prevalence of wasting and stunting in these children were low $(10.3 \% \& 15.7 \%$ respectively) with boys suffering more than girls in both aspects. The 6-10 years old children were affected most. Pediculosis, Dental caries and Worm infestation were three most common diseases suffered by students. The study highlighted the need for continuation of school health services aimed at improvement of their health \& nutritional status.

\section{Key Words: School Children, Health Status, Wasting, Stunting.}

\section{INTRODUCTION}

Health status of school children is of paramount importance, because the foundation for lifetime and strength is laid during this period. School children are prone to protein energy malnutrition as a result of diet limitation, lack of adequate calories and protein, all dependent upon total amount of food intake. Malnutrition during this critical phase of growth can lead not only to shunting of physical growth but also to sub optimal intellectual development and poor neuro-integrative competence in children. There are concerted efforts to provide care to under 5 children through various national maternal and child health programs. The 5-16 years age group appears to remain a neglected lot. School children constitute a large pool of children of this age group. Various types of government sponsored school health programs have been launched but school health services are inadequate, intermittent limited to the urban \& few favored schools. The 5-16 years old children are on the threshold of adulthood. If they are to reach adulthood in a healthy state, then it is necessary to provide specifically targeted and concerted health services to improve their health status. The present study was carried out to find out the health status of school children in Pokhara valley.

\section{MATERIALS AND METHOD}

Physical examination of all students in age group 4-15 years of 6 government primary schools of northern part of Pokhara valley, was carried out by a health team consisting of medical students (seventh semester, 1998 batch) interns and faculty of the department of SPM, Manipal College of Medical Science. Study conducted from Jan-June 2001. Height (in cm) and weight (in $\mathrm{Kg}$ ) were recorded. Anemia was diagnosed from clinical signs such as pallor of the conjunctiva/tongue. The

* Manipal College of Medical Sciences \& Manipal Teaching Hospital, Pokhara, Nepal.

Address for correspondence : Dr. Lochana Shrestha

Dept. of Community Medicine

Manipal College of Medical Sciences, Pokhara, Nepal

Email: shresthalochana@yahoo.com 
mean weight and height of the children according to age and sex were compared with the median weight for age and height for age as per ICMR standards ${ }^{1}$. Nutritional status of the studied children was assessed through weight for age (wasting) and height for age (stunting) according to waterlow classification.

\section{RESULTS \& DISCUSSION}

A total of 750 students of both sexes ( 368 boys and 382 girls) in the age groups of 4 years to 15 years were examined. (Table I)
On an average the boys at age 7 and the girls at age 12 were found to significantly taller than the girls and boys respectively. At ages 4, 5, 6, 8 and 10 years the boys were taller than girls and in remaining ages girls were taller than boys, but these differences were statistically not significant. (Table II)

On an average the girls weighed significantly more than the boys at ages 11, 12, 13 and 14. At the remaining ages the boys were weighed more than girls, but these differences were statistically not significant. (Table III)

Table I : Distribution of children by age and sex 